\title{
The global scope of ENT
}

The term 'global health' refers to the health of populations in a global sense, in that it transcends national borders. The underlying premise is an attempt to achieve equity in health care for all of the world's people. Of course, the present state is far from this ideal, with huge inequalities existing, from the extremes of no health care access for some versus wasteful over-investigation and over-treatment for others.

The global health stage has been dominated by communicable diseases, such as human immunodeficiency virus infection, malaria and tuberculosis, and the issues of maternal and child health. As a result, ENT and head and neck disorders have received little attention, despite being major public health concerns.

According to the World Health Organization, 'The conditions that affect the largest number of individuals at any given moment are not dramatic, and are thus easily overlooked and underestimated'. ${ }^{1}$ Deafness is the world's commonest disability and has profound effects. Worldwide, most severely deaf children fail to develop normal speech and language. Deaf adults have difficulty finding employment, and the elderly deaf are often socially isolated. Deafness due to chronic otitis media, ototoxic drugs and excessive noise exposure is increasing. In developed countries, age-related sensorineural deafness is increasingly prevalent, in line with increasing life expectancy.

Head and neck cancer is a major problem in poorer countries where tobacco and alcohol consumption is on the increase. Disease often presents at a late stage, and there are economic barriers to diagnosis and treatment.

The Journal of Laryngology \& Otology has always had an international outlook and continues to be aimed at the ENT community as a whole. In this issue $^{2-5}$ and those following, we have invited selected authors to present their experience of developing ENT services in poorer countries. In addition, the JLO Digital Archive provides a readily available resource for ENT practitioners worldwide, enabling access to a huge database of articles relevant to the global health agenda and its ENT perspective. Some of these articles provide accounts of contemporary management of conditions seen more commonly in poorer countries. ${ }^{6,7}$ Others present innovative ways of managing common conditions. ${ }^{8,9}$ Finally, there are accounts of the unique health problems encountered in hostile environments. ${ }^{10}$ The JLO Digital Archive is a rich resource which we hope many of our readers will find informative and fascinating.

JOHANNES J FAGAN
NICHOLAS STAFFORD
Guest Editors
ROBIN YOUNGS
Senior Editor

References

1 World Health Organization, Health Statistics and Health Information Systems, The global burden of disease: 2004 update. In: http://www.who.int/healthinfo/global_burden_disease/2004_report_update/en/index.html [17 February 2012]

2 D'Cruz AK, Sharma S, Pai PS. Current status of near total laryngectomy: review. J Laryngol Otol 2012;126:556-562

3 Aswani J, Baidoo K, Otiti J. Establishing a head and neck unit in a developing country. J Laryngol Otol 2012;126:552-555

4 Fagan JJ. Developing world ENT: A global responsibility. J Laryngol Otol 2012;126:544-547

5 Harris T, Peer S, Fagan JJ. Audiological monitoring for ototoxic tuberculosis, human immunodeficiency virus and cancer therapies in a developing world setting. J Laryngol Otol 2012;126: 548-551

6 Saedi B, Sadeghi M, Seilani P. Endoscopic management of rhinocerebral mucormycosis with topical and intravenous amphoteracin B. J Laryngol Otol 2011;125:807-10

7 Effat KG, Madany NM. Microbiological study of role of fungi in primary atrophic rhinitis. J Laryngol Otol 2009;123:631-4

8 Snidvongs K, Vatanasapt P, Thanaviratatananich S, Pothaporn M, Supiyaphun P. Outcome of mobile ear surgery units in Thailand. J Laryngol Otol 2010;124:382-6

9 Maung KH, Tun T, Stafford ND. Do-it-yourself grommets. J Laryngol Otol 2011;125:1268-9

10 Prasad BK. ENT morbidity at high altitude. J Laryngol Otol 2011;125:188-92 